\title{
Marketing decision support systems: Adoption, use, and satisfaction ${ }^{1}$
}

\author{
Berend Wierenga $^{\text {a, * }}$, Peter A.M. Oude Ophuis ${ }^{\text {b.2 }}$ \\ a Department of Marketing, Rotterdam School of Management, Erasmus University, Rotterdam, The Netherlands \\ ${ }^{\mathrm{b}}$ Digital Valley Internet Providers, Wageningen, The Netherlands
}

Accepted 14 April 1997

\begin{abstract}
This paper deals with marketing decision support systems (MDSS) in companies. In a conceptual framework five categories of factors are distinguished that potentially affect adoption, use, and satisfaction: external environment factors, organizational factors, task environment factors, user factors and implementation factors. Hypotheses are developed and tested on data from a survey of 525 companies. The factors that determine the adoption of an MDSS are different from the factors that affect the success of an MDSS, once it has been installed. For adoption, support from inside the company, communication and knowledge about MDSS are crucial. For the subsequent success of an MDSS, involvement of the user, sophistication, adaptability of the system and the possibility of direct interaction with the system are important. MDSS are primarily adopted to obtain information and not to upgrade (add value to) existing information. Companies in consumer goods are ahead of companies in the business-to-business sector, but this difference is likely to decrease in the future. (c) 1997 Elsevier Science B.V.

Keywords: Marketing decision support systems (MDSS); Decision support systems (DSS); Information systems; Adoption of (marketing) decision support systems; Use of (marketing) decision support systems; Satisfaction with (marketing) decision support systems; Implementation of (M)DSS in companies; Information technology (IT) in marketing
\end{abstract}

\section{Introduction}

As marketing decisions are becoming more complex — because of the proliferation of products and

\footnotetext{
${ }^{*}$ Corresponding author. Tel.: +31-10-4081969: fax: +31-102120544: e-mail: bwierenga@fac.fbk.eur.nl.

'The authors wish to thank two anonymous reviewers, and Gerrit van Bruggen, Ale Smidts (Erasmus University Rotterdam) and Eelko Huizingh (University of Groningen) for their useful comments on earlier versions of this manuscript.

${ }^{2}$ At the time of this research Peter Oude Ophuis was with the Department of Marketing and Marketing Research, Wageningen Agricultural University, The Netherlands.
}

brands and, under the pressure of competition, an ever shorter time frame for the decision-making process - decision support tools are of increasing importance for management. The 'marketing information revolution' is producing enormous amounts of data, and systems are needed to translate these data into actionable information. Major developments in information technology (computers, telecommunication, database management systems, knowledge based systems) and analytical capabilities (data analysis techniques, simulation and optimization methods) have provided the means to create systems that support decisions by the marketing 
manager. Many companies now take a systematic approach to the application of IT in marketing by installing so-called marketing decision support systems (MDSS).

Little (1979) gives the following definition:

... a marketing decision support system is a coordinated collection of data, systems, tools and techniques with supporting software and hardware by which an organization gathers and interprets relevant information from business and environment and turns it into a basis for marketing action.

Companies are recognizing the strategic importance of such marketing decision support systems and are stepping up their investments in information technology for marketing. Higby and Farah (1991) found that in the US, $32 \%$ of the companies had installed some form of marketing decision support system $^{3}$. In The Netherlands, Van Campen et al. (1991) estimated the penetration of marketing decision support systems at $37 \%{ }^{4}$. According to Shaw (1994), in the UK the percentage of total IT spending of companies that go to marketing is already $15 \%$ and this percentage is likely to rise. Companies would not spend all this money if they were not convinced that MDSS does help. The effectiveness of MDSS in leading to better, more profitable decisions has also been demonstrated in experimental work (Van Bruggen, 1993; Van Bruggen et al., 1996).

The investments for MDSS can be substantial. In a study in The Netherlands, it was found that the median investment in the development and implementation of an MDSS amounted to US $\$ 120,000$ (Van Campen et al., 1991). It is important that this money be spent for MDSS that are as effective as possible.

Although there are occasional studies that give information about the presence and use of such systems in practice (e.g., Moriarty and Swartz, 1989), there is a lack of systematic insight into the factors that affect the adoption of MDSS in companies and the factors that determine the success of an MDSS once it has been installed. Such insight could stimu-

\footnotetext{
${ }^{3}$ Based on a survey among marketing executives $(n=212)$.

${ }^{4}$ Based on a survey among companies with over 10 employees and a marketing manager present $(n=525)$.
}

late the dissemination of MDSS and would be useful both for suppliers and designers of MDSS and for companies that want to implement effective MDSS. Specifically, in this study we look at the factors that affect adoption and use of, and satisfaction with an MDSS. For this purpose we will use data from 525 companies in The Netherlands.

We first present a conceptual framework and formulate hypotheses about the factors that affect adoption of, use of, and satisfaction with MDSS. Then we describe the data and carry out analyses to test the hypothesized relationships. Next, the results are presented and discussed and we end with a section on limitations of the study and directions for further research.

\section{Conceptual framework and hypotheses}

In our conceptual framework (Fig. 1) we distinguish the following stages with respect to an MDSS

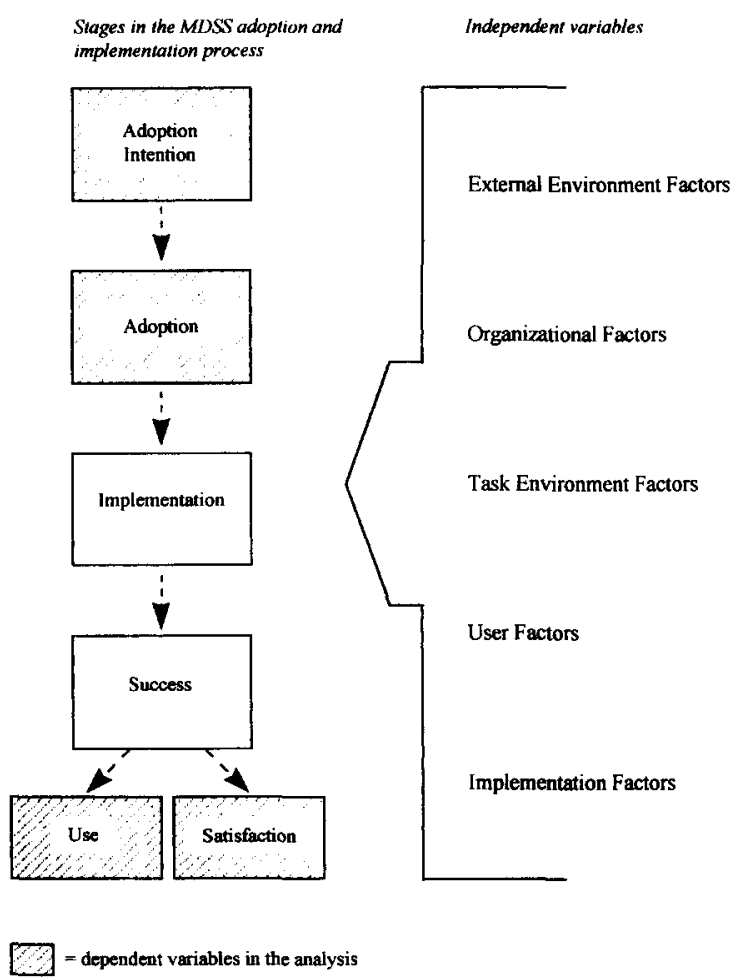

Fig. 1. Conceptual framework of the factors that affect adoption (intention) and success of MDSS. 
in a company: adoption intention, adoption, and implementation, which in turn leads to (some level of) success. In this study we are interested in the variables that determine adoption (and adoption intention of companies that have not adopted yet) and in the variables that determine success. So, basically we look at two stages of the adoption and implementation process of an MDSS: (i) the adoption (intention) of an MDSS by a company, and (ii) the success of the MDSS, once it has been adopted and implemented. From the many variables that might be considered as indicators for success of an MDSS, we take use and satisfaction here. In the (general) decision support systems (DSS) literature, use and satisfaction are the variables most often used as success indicators for DSS (Delone and McLean, 1992; Alavi and Joachimsthaler, 1992).

The variables adoption, adoption intention, use, and satisfaction are the dependent variables in this study. As far as the independent variables are concerned (right-hand-side of Fig. 1), we use the following five categories: external environment factors, organizational factors, task environment factors, user factors, and implementation factors. Four of these categories were included in the meta-analysis by Alavi and Joachimsthaler (1992) of the factors that determine the implementation success of DSS. However, they did not include implementation factors, which we think are important elements for the success of (M)DSS. In the following discussion of the hypotheses, more information will be given about the specific variables employed within each of the categories.

There are three areas in the literature from which we derive our hypotheses.

(i) Marketing. At several places in the marketing literature discussions can be found about the factors that determine the successful implementation of marketing decision support systems, or marketing models (i.e., components of marketing decision support systems). Little (1970) mentions several characteristics of a marketing model that enhance its use. For example, a model should be simple, robust, complete on important issues, easy to communicate with, and adaptive. Lilien et al. (1992) stress the importance of (top-)management support and user involvement in the development/implementation process for a successful MDSS. In Blattberg et al. (1994), the impor- tance of data for the development of successful MDSS is emphasized.

(ii) Decision support systems. In the area of general decision support systems or information systems (IS), the tradition of empirical implementation studies goes back to the seventies (for example, Schultz and Slevin, 1975 and Lucas, 1975). Examples of more recent studies which are of specific importance for the present work are Kwon and Zmud (1987), Delone and McLean (1992) and Alavi and Joachimsthaler (1992).

(iii) Innovation. The adoption of an MDSS can be seen as the acceptance of a technological/organizational innovation. According to Swanson (1994) the theory on IS-innovation cannot be distinguished from the general theory on organizational innovation. For this reason theories about the adoption of innovations by companies (see, e.g., Zaltman et al., 1973; Gatignon and Robertson, 1989) were used to develop our hypotheses.

\subsection{Adoption and adoption intention}

We first discuss the variables that we expect will have an impact on the adoption of an MDSS. Here the question is: what are the characteristics of companies and their environment that makes them more amenable to the adoption of MDSS than other companies? We expect the same variables to be relevant for adoption and adoption intention. In the discussion of our hypotheses we follow the classification given on the right hand side of Fig. 1.

\subsubsection{External environment factors}

Customer heterogeneity and uncertainty foster innovativeness in information systems (Kwon and Zmud, 1987). More dynamic environments require more (non-financial) data (Ewusi-Mensah, 1981). Demand uncertainty is expected to increase the likelihood of adoption of information technology for sales support (Gatignon and Robertson, 1989).

In the business-to-business sector the marketing concept has been adopted later than in consumer products. Also in the business-to-business sector the availability of data is generally lower. Therefore, "(marketing decision) systems for industrial products clearly lag the consumer packaged goods industry" (Mohan and Holstein, 1994). 
Our hypotheses with respect to external environmental factors are the following ${ }^{5}$ :

HA 1. Companies in a more dynamic environment are more likely to adopt an MDDS (ENVDYN) ${ }^{6}$.

$H A$ 2. Companies in business-to-business environments are less likely to adopt MDSS than consumer product companies (BBCONSMA).

\subsubsection{Organizational factors}

The company size has been found to be positively related to the adoption of an innovation (Kennedy, 1983; Swanson, 1994). Centralization of an organization generally is negatively related to its willingness to adopt new information technologies (Zaltman et al., 1973; Zmud, 1982; Kwon and Zmud, 1987). Decentralization creates a need for more effective computer-based information systems (Montazemi, 1988).

There seems to be overwhelming agreement in the (M)DSS literature that top management support is an important success factor for decision support systems (Zmud, 1979; Kwon and Zmud, 1987; Lilien et al., 1992; Lee and Kim, 1992). For organizational factors our hypotheses are as follows:

$H A$ 3. Larger companies are more likely to adopt an MDSS than smaller companies (COMPSIZE).

HA 4. More centrally organized companies are less likely to adopt an MDSS than less centrally organized companies (CENTRAL).

HA 5. Top management support fosters the adoption of an MDSS (TOPMSUPP).

\subsubsection{Task environment factors}

Task environment factors refer to elements within the marketing domain of a company. The development of an MDSS requires a certain sophistication level of marketing in a company, reflected by the organization of marketing (the presence of a marketing department, the use of an annual marketing plan, for example) and by the availability of resources for marketing (marketing staff, hardware, software). As

\footnotetext{
${ }^{5}$ The hypotheses are indicated with a letter (for example A stands for adoption) and a number.

${ }^{6}$ ENVDYN is the name of the variable in the analysis corresponding with this hypothesis. For the other hypotheses the corresponding variables are indicated in a similar way.
}

a company has more marketing information available, it will need better tools to analyze this information, hence the drive towards an MDSS will become stronger. Support from colleagues for an MDSS is an indication of a positive attitude towards MDSS in the marketing department. The number of information sources by means of which a company becomes aware of a new technology is an important factor (Zaltman et al., 1973; Gatignon and Robertson, 1989). Apparent success of other innovators motivates imitative behavior (Swanson, 1994).

We have the following hypotheses with respect to the relationship between task environment factors and adoption.

HA 6. Companies with a more advanced marketing organization are more likely to adopt an MDSS than companies with a less advanced marketing organization (MARKORG).

HA 7. As a company has more resources available for marketing, the likelihood that it will adopt an MDSS is higher (MRESOURC).

$H A$ 8. The more marketing information a company has, the higher is the likelihood that a company will adopt an MDSS (INFO).

HA 9. A positive attitude towards MDSS among the people in the marketing department favors the adoption of an MDSS (COLLSUPP).

HA 10. The number of information sources about MDSS is positively related to the adoption of an MDSS (INFOSRCS).

HA 11. Knowledge of successful applications of MDSS in other companies increases the likelihood of adoption in one's own company (SUCCOTHER).

\subsection{Use and satisfaction}

\subsubsection{External environment, organizational and task environment factors}

The independent variables of the right hand side of Fig. 1 can be divided into two groups: (i) external environment factors, organizational factors and task environment factors, and (ii) user factors and implementation factors. We expect that the first group of variables affects the adoption of an MDSS (according to the hypotheses just formulated) and that the second group affects the success of an MDSS once it is adopted and implemented. In this view, MDSS- 
success is not affected by external environment factors, organizational factors and task environment factors. This view seems to concur with the dominant approach in empirical studies of DSS success, where these 'contextual' variables have not received systematic attention (Alavi and Joachimsthaler, 1992). However, in the current study we check this explicitly, using the following hypotheses.

$H U l$. The use of an MDSS is not systematically affected by external environment factors, organizational factors or task environment factors.

$H S$ 1. The satisfaction with an MDSS is not systematically affected by external environment factors, organizational factors or task environment factors.

\subsubsection{User factors}

Age has been found to be positively related to information search and hence the use of an MDSS (Taylor, 1975; Lucas, 1975; Zinkhan et al., 1987). However, older decision makers tend to be less familiar with computers, therefore they will be less satisfied with the MDSS itself and with the decisions reached when using the MDSS (Zinkhan et al., 1987).

Managers with more education are better able to understand an MDSS and take advantage of its possibilities (Vasarhelyi, 1977), which will stimulate use and satisfaction.

A more experienced manager has more knowledge about the specific problems and consequently is able to employ an MDSS to more avail. Work experience has been found to have an overall positive effect on implementation success of DSS (Zinkhan et al., 1987; Alavi and Joachimsthaler, 1992). Involvement in automation results in more use of an MDSS by a manager (Zinkhan et al., 1987) and DSS experience in general has a strong effect on implementation success of a DSS (Alavi and Joachimsthaler, 1992).

We have the following hypotheses with respect to the effect of user factors on use and satisfaction.

$H U$ 2. Older users will use an MDSS more intensively (AGE).

$H U$ 3. Education is positively related to MDSS use (EDUC).

$H U$ 4. More experienced users will use the MDSS more intensively (EXPER).
$H U$ 5. Involvement in automation is positively related to MDSS use (INVAUT).

$H S$ 2. Older users are less satisfied with the MDSS (AGE).

$H S$ 3. Higher educated users are more satisfied with the MDSS (EDUC).

$H S$ 4. More experienced users are more satisfied with the MDSS (EXPER).

HS 5. Users who are more involved in automation are more satisfied with the MDSS (INVAUT).

\subsubsection{Implementation factors}

Whereas Alavi and Joachimsthaler (1992) in their meta-analysis of DSS implementation research, basically limit themselves to user factors, in the present study we also have data on specific implementation factors of MDSS. Since the way an MDSS is implemented can be expected to have consequences for its success, we include the implementation factors in the present analysis.

An MDSS can either be purchased as a commercial package or developed in the company. The trade-off is between faster implementation and lower costs with a commercially purchased package and more flexibility and a better fit with the specific situation for a customer-developed system (Lucas et al., 1988). This latter consideration implies a relative disadvantage of a commercial package as far as use and satisfaction are concerned.

User involvement in the implementation of a DSS is generally found to be important for its success (King and Rodriquez, 1981; Alavi, 1982; Ives and Olson, 1984; Kwon and Zmud, 1987; Lilien et al., 1992). Also the presence of a person in the organization who fiercely propagates and stimulates a DSS, i.e., a 'champion', contributes to its success (Sviokla, 1989).

In the literature adaptability, also called flexibility, of an MDSS has been discussed as an important factor for DSS success (Little, 1970; Barki and Huff, 1990; Udo and Davis, 1992). Another factor is sophistication of an MDSS. Sophistication refers to the type of questions that an MDSS is able to answer: 'What'. 'Why', 'What-if', or 'What-Should' questions (Wierenga et al., 1994). These questions form a hierarchy and a more sophisticated MDSS is able to answer questions that are higher in the hierarchy. Sophistication of an (M)DSS has not been researched much in the literature so far. It may be 
expected to have a positive effect on MDSS success.

There is a tendency towards introducing company-wide information systems, with modules for different functional areas such as marketing. This implies that individual functional areas cannot completely determine their own specifications but must adhere to standards set at a higher level. This might decrease the implementation success of a system within the marketing department. Finally it seems important for the success of an MDSS that a manager can directly interact with the MDSS through a PC or laptop on his/her desk instead of obtaining the information from the MDSS through an intermediary.

In summary, our hypotheses with respect to the effects of implementation factors on the use of and satisfaction with an MDSS are the following.

$H U 6 \& H S 6$. A commercially purchased package has a negative effect on use and satisfaction, compared to a customer-developed system (COMMPACK).

$H U 7 \& H S 7$. A larger role of marketing in the development process of an MDSS has a positive effect on use and satisfaction (MARKROLE).

$H U 8 \& H S$ 8. A greater perceived participation of the users in the implementation process of the MDSS has a positive effect on use and satisfaction (PERCPART).

$H U 9 \& H S 9$. The presence of an MDSS Champion in the company enhances use and satisfaction (MDSSCHMP).

$H U 10 \& H S 10$. More adaptable systems lead to more use and higher levels of satisfaction (ADAPT).

$H U 11 \& H S 11$. More sophisticated systems are used more intensively and generate higher levels of satisfaction (SOPHISTC).

$H U 12 \& H S 12$. MDSS that are connected to other (non-marketing) systems in the company are used less and produce less satisfaction than MDSS of a stand-alone type (CONNECT).

$H U 13 \& H U 13$. The possibility of a manager to directly interact with the MDSS is a positive factor for use as well as satisfaction (INTERACT).

\subsubsection{The relationship between use and satisfaction}

In this study, use and satisfaction are treated as two distinct factors, both indicators of the success of an MDSS. The question may be asked: to what extent are use and satisfaction related? One possible answer is that one of these factors influences the other. The question then is: which factor influences which? From a conceptual point of view it is plausible that use leads to satisfaction, but it is also possible that the greater the satisfaction, the more an MDSS is used. In the literature no unequivocal evidence can be found about the direction of the effect. Baroudi et al. (1986) found that satisfaction influences usage. Zinkhan et al. (1987), on the other hand, concluded that usage influences satisfaction. Another possibility is that use and satisfaction are just correlated because they are influenced by a common factor (Gelderman, 1995). However this may be, it seems appropriate to include the relationship between use and satisfaction in the analysis. Here we treat use and satisfaction symmetrically: satisfaction is included in the analysis for the explanation of use and use in the analysis for the explanation of satisfaction, and our hypotheses are:

$H U 14 \& H S 14$. There is a positive relationship between use and satisfaction.

\section{Data}

On the basis of a commercially available database, which contained information about all enterprises with 10 or more employees in The Netherlands, a sampling frame was selected which consisted of 2924 companies that had a designated marketing manager. The rationale behind this procedure was the notion that in order to 'hit' an acceptable number of companies with an MDSS, these companies probably should have a substantial size (10 or more employees) and have formalized their marketing function (a designated marketing manager or equivalent). From this sampling frame a sample of 1014 companies was drawn.

A total of 525 managers were willing to cooperate in the study and to complete the interview, which was carried out using computer-assisted telephone interviewing (Sawtooth, 1989). The actual data collection took place in April-May, 1990. The net response rate was $52 \%$. This is a relatively high percentage, given that marketing managers have busy schedules. The main reason for non-participation was the impossibility to schedule an interview session 
within the designated period. Generally there was a lot of interest in the topic among the managers, also among those who were not able to participate. We have no reason to presume the existence of a bias in the data caused by the non-response, also because there are no systematic differences in response rates between different industries, size classes of companies, and regions.

During the interview the response to a specific filter question was used as the discriminator for subsequent questions regarding MDSS. For the exact formulation of that question, see Appendix A (under Adoption). One hundred and ninety four (194) respondents $(37 \%)$ answered this question affirmatively. These respondents answered a number of specific questions about their MDSS in addition to the questions that all respondents answered. The variables and their measurement are described in Appendix A. As is indicated there, several of the independent variables in this study have been derived by means of factor analysis from a set of multiple measurements.

\section{Results}

To test our hypotheses, multiple regression was performed on the dependent variables of adoption, adoption intention, use, and satisfaction. Since adoption is a binary variable, the multivariate analysis for this variable was, analogous to Gatignon and Robertson (1989), performed as a logistic regression.

Three different sample sizes apply. For the analysis of adoption the full sample $(n=525)$ was used. For the analysis of adoption intention by non-adopters the data of the non-adopters $(n=329)$ were used. For the analysis of use and satisfaction only the data of the adopters ( $n=194$ ) could be used (for two of the non-adopters the questionnaire was too incomplete for further analysis).

The results of the multivariate analyses are presented in Tables 1 and 2. For those explanatory variables for which, on the basis of our hypotheses, we expected specific relationships with the dependent variable, but which turned out to be non-significant in the multivariate analysis, bivariate correlation coefficients with the dependent variable were also computed. Where applicable, the results of these bivariate analyses will be mentioned in the text.

\subsection{Adoption and adoption intention}

\subsubsection{Adoption}

Adoption is a yes/no variable measured over the whole sample $(n=525)$. Based on the significance of the regression coefficients in Table 1, the follow-

Table 1

Regression results for adoption and adoption intention

\begin{tabular}{|c|c|c|c|c|c|c|c|}
\hline \multirow[t]{2}{*}{ Independent variables } & \multicolumn{2}{|c|}{ Hypothesis } & \multicolumn{2}{|c|}{ Adoption $(n=525)$} & \multicolumn{3}{|c|}{ Adoption intention $(n=329)$} \\
\hline & & & regr.cft & $\operatorname{sig}(p)$ & betaweight & $\operatorname{sig}(p)$ & tolerance \\
\hline \multicolumn{8}{|c|}{$\overline{\text { External environment factors }}$} \\
\hline ENVDYN & + & HA 1 & 0.158 & 0.17 & 0.030 & 0.58 & 0.93 \\
\hline BBCONSMA & - & HA2 & $-0.215^{*}$ & 0.09 & 0.054 & 0.32 & 0.96 \\
\hline \multicolumn{8}{|l|}{ Organizational factors } \\
\hline COMPSIZE & + & HA3 & 0.148 & 0.22 & $0.108^{* *}$ & 0.05 & 0.90 \\
\hline CENTRAL & - & HA4 & 0.085 & 0.32 & -0.013 & 0.81 & 0.96 \\
\hline TOPMSUPP & + & HA5 & $0.201^{* *}$ & 0.04 & 0.038 & 0.51 & 0.82 \\
\hline \multicolumn{8}{|c|}{ Task environment factors } \\
\hline MARKORG & + & HA6 & 0.169 & 0.047 & $0.121^{* *}$ & 0.03 & 0.91 \\
\hline MRESOURC & + & $\mathrm{HA} 7$ & 0.164 & 0.21 & 0.068 & 0.21 & 0.94 \\
\hline INFO & + & HA8 & $0.214^{*}$ & 0.06 & $-0.147^{* *}$ & 0.01 & 0.95 \\
\hline COLLSUPP & + & HA9 & $0.364^{* *}$ & 0.00 & $0.270^{* *}$ & 0.00 & 0.71 \\
\hline INFOSRCS & + & HA10 & 0.040 & 0.46 & $0.167^{* *}$ & 0.01 & 0.71 \\
\hline \multirow[t]{2}{*}{ SUCCOTHR } & + & HA1 1 & $0.910^{* *}$ & 0.00 & $0.101^{*}$ & 0.08 & 0.79 \\
\hline & & & $X_{11}^{2}=84.17$ & $(p<0.000)$ & $R_{\mathrm{adj}}^{2}=0.165$ & $(p<0.000)$ & \\
\hline
\end{tabular}

\footnotetext{
* Significant at $\alpha \leq 0.10 ;{ }^{* *}$ significant at $\alpha \leq 0.05$.
} 
Table 2

Regression results for use and satisfaction

\begin{tabular}{|c|c|c|c|c|c|c|c|c|}
\hline \multirow{2}{*}{$\begin{array}{l}\text { Independent } \\
\text { variables }\end{array}$} & \multicolumn{3}{|c|}{ Use $(n=194)$} & \multicolumn{5}{|c|}{ Satisfaction $(n=194)$} \\
\hline & hypothesis & betaweight & $\operatorname{sig}(p)$ & \multicolumn{2}{|c|}{ hypothesis } & betaweight & $\operatorname{sig}(p)$ & tolerance $^{\mathrm{a}}$ \\
\hline \multicolumn{9}{|c|}{ External environment factors } \\
\hline ENVDYN & 0 & 0.002 & 0.98 & 0 & & 0.065 & 0.33 & 0.85 \\
\hline BBCONSMA & 0 & 0.015 & 0.85 & 0 & & 0.081 & 0.22 & 0.87 \\
\hline \multicolumn{9}{|c|}{ Organizational factors } \\
\hline COMPSIZE & 0 & 0.021 & 0.80 & 0 & & -0.043 & 0.54 & 0.80 \\
\hline CENTRAL & 0 & 0.086 & 0.28 & 0 & & -0.015 & 0.83 & 0.89 \\
\hline TOPMSUPP & HU 1 & 0.077 & 0.41 & 0 & HS $1 * * *$ & 0.115 & 0.15 & 0.69 \\
\hline \multicolumn{9}{|c|}{ Task environment factors } \\
\hline MARKORG & 0 & 0.017 & 0.83 & 0 & & 0.054 & 0.43 & 0.82 \\
\hline MRESOURC & 0 & -0.030 & 0.71 & 0 & & 0.087 & 0.22 & 0.79 \\
\hline INFO & 0 & -0.085 & 0.32 & 0 & & 0.101 & 0.16 & 0.82 \\
\hline COLLSUPP & 0 & -0.014 & 0.87 & 0 & & 0.007 & 0.93 & 0.68 \\
\hline INFOSRCS & 0 & -0.045 & 0.62 & 0 & & 0.063 & 0.43 & 0.65 \\
\hline SUCCOTHR & 0 & 0.025 & 0.76 & 0 & & 0.008 & 0.92 & 0.73 \\
\hline \multicolumn{9}{|l|}{ User factors } \\
\hline AGE & HU 2 & $0.172^{*}$ & 0.08 & - & HS 2 & 0.053 & 0.54 & 0.83 \\
\hline EDUC & HU 3 & 0.052 & 0.50 & + & HS 3 & -0.071 & 0.29 & 0.82 \\
\hline EXPPER & HU 4 & -0.167 & 0.11 & + & HS 4 & 0.097 & 0.29 & 0.79 \\
\hline INVAUT & HU 5 & $0.180^{* *}$ & 0.03 & + & HS 5 & $-0.136^{*}$ & 0.06 & 0.74 \\
\hline \multicolumn{9}{|c|}{ Implementation factors } \\
\hline COMMPACK & HU 6 & 0.021 & 0.80 & - & HS 6 & -0.010 & 0.89 & 0.81 \\
\hline MARKROLE & HU 7 & -0.085 & 0.30 & + & HS 7 & 0.051 & 0.47 & 0.77 \\
\hline PERCPART & HU 8 & 0.005 & 0.95 & + & HS 8 & $0.159^{* *}$ & 0.03 & 0.82 \\
\hline MDSSCHMP & HU 9 & 0.027 & 0.33 & + & HS 9 & 0.002 & 0.97 & 0.80 \\
\hline ADAPT & HU 10 & 0.009 & 0.92 & + & HS 10 & $0.363^{* *}$ & 0.00 & 0.74 \\
\hline SOPHISTC & HU 11 & $0.220^{* *}$ & 0.01 & + & HS 11 & 0.093 & 0.22 & 0.68 \\
\hline CONNECT & HU 12 & -0.055 & 0.47 & - & HS 12 & 0.030 & 0.65 & 0.88 \\
\hline INTERACT & HU 13 & $0.383^{* *}$ & 0.00 & + & HS 13 & $0.237^{* *}$ & 0.00 & 0.72 \\
\hline Satisfaction & HU 14 & 0.033 & 0.32 & & & & & \\
\hline \multirow[t]{2}{*}{ Use } & & & & + & HS 14 & 0.027 & 0.72 & 0.70 \\
\hline & \multicolumn{2}{|l|}{$R_{\mathrm{adj}}^{2}=0.195$} & $(p<.000)$ & \multicolumn{2}{|c|}{$R_{\mathrm{adj}}^{2}=0.397$} & $(p<.000)$ & & \\
\hline
\end{tabular}

* Significant at $\alpha \leq 0.10 ;{ }^{* *}$ significant at $\alpha \leq 0.05 ;{ }^{* * *}$ HS 1 refers to all the zeroes in this column.

${ }^{a}$ The tolerances in the regression with use as dependent variable are very similar. In that regression the tolerance of satisfaction is 0.54 . 
ing hypotheses with respect to adoption are confirmed: adoption of MDSS is higher in companies with support for MDSS from top management (HA 5 ), in companies with support for MDSS from marketing colleagues (HA 9), and in companies with awareness of successful MDSS applications in other companies (HA 11). Furthermore there is a tendency (alpha $<0.10$ ) that adoption is lower in companies with industrial (business-to-business) products compared to consumer product companies (HA 2), and higher in companies with more market information available (HA 8).

The effects of all the non-significant variables, except the variable centralization, are in the hypothesized direction. Four variables, company size, marketing organization, marketing resources and information sources about MDSS - for which no significant effect is found in the multivariate analysis do show a significant relationship with adoption when a bivariate correlation is computed. The directions of these bivariate relationships are in agreement with the hypotheses HA 3, HA 6, HA 7, and HA 10 , respectively. Apparently, in the multivariate analysis these effects are suppressed by the presence of other variables.

For example, in the bivariate analysis, company size is positively related to adoption, implying that, statistically speaking, larger companies more often have an MDSS than smaller companies. However, company size is also positively related to top management support and support from colleagues, i.e., in larger companies there is a more positive attitude towards MDSS among top management and colleagues than in small companies. Apparently, the effect of company size on adoption 'runs through' the effect on attitudes with respect to MDSS. If these variables are also put into the equation, they 'take over' the effect of company size. Something similar happens to marketing organization, marketing resources and information sources about MDSS.

\subsubsection{Adoption intention}

Based on the results of the multivariate analysis given in Table 1 , it can be concluded that adoption intention is higher for larger companies (HA 3 confirmed) and for companies with a more advanced marketing organization (HA 6 confirmed). In con- trast, with the explanation of adoption we do find effects for these variables in the multivariate analysis. Furthermore, adoption intention is higher as there is more support from marketing colleagues (HA 9), and as there are more information sources about MDSS (HA 10). The expected positive effect of knowing about successful MDSS applications in other companies (HA 11) almost reaches significance level. Again, a favorable attitude of colleagues and information about MDSS turn out to be very important.

With respect to the amount of marketing information that a company has, the estimated effect is significant, but with a direction opposite from what we expected. Adoption intention is higher as one has less information instead of more. Apparently an MDSS is seen primarily as a device for obtaining information, and not for the upgrading of already existing information. Also we find that, contradictory to our HA 2, adoption intention is not lower for companies primarily in business-to-business products, as compared to consumer goods companies. (For actual adoption this hypothesized relationship was on the verge of significance.)

Centralization and top management support are not significant in the multivariate analysis, but in a bivariate analysis they show a significant relationship in the hypothesized direction with adoption intention (HA 4 and HA 5).

Considering the results for adoption and adoption intention, it can be concluded that most of the explanatory variables showed the expected effects. In some cases an effect did not appear in the multivariate analysis, but could still be traced back as a factor working indirectly through one of the other variables. For two variables, business-to-business vs. consumer products company and the amount of market information available, the directions of the observed effects on adoption intention were different from expected. Only one explanatory variable, environmental dynamics, did not show any significant effect, either in the multivariate or in the bivariate analyses. Indeed, it might be that this factor does not affect adoption of MDSS. Gatignon and Robertson (1989) also did not find a significant effect for this variable in their empirical results. Another possibility is that a more elaborate measurement scale is needed to find effects of environmental dynamics. 


\subsection{Use}

The results of the analysis for use (and satisfaction) are given in Table 2.

The first conclusion to be drawn from Table 2 is that the external environment, organizational and task environment factors are not significantly related to use (nor to satisfaction). This confirms our hypotheses, HU 1 and HS 1 , that these factors, although they affect the adoption of an MDSS, are not systematically related to the success of the MDSS, once it is implemented.

With respect to the other two categories of independent variables, user factors and implementation factors, the results of Table 2 show that respondents who are more involved in automation (HU 5), who have more sophisticated MDSS (HU 11), and who use the MDSS through direct interaction with the system (HU 13) make more use of the MDSS. The expected higher use of the MDSS by older respondents (HU 2) is almost significant. Of the remaining non-significant, independent variables, seven out of ten have a sign in the hypothesized direction. For three variables this is not the case. Only for one of these latter cases is the $p$-level anywhere close to 0.05 , namely experience $(p=0.11)$.

Whether or not there is an MDSS champion, a variable that is not significant in the multivariate analysis does have a significant relationship with use in a bivariate analysis. The direction of this bivariate relationship is in accordance with hypothesis HU 9. Satisfaction has a bivariate correlation coefficient with use of $0.15(p=0.07)$. So, the common variance of satisfaction and use is less than $3 \%$, which supports our decision to treat use and satisfaction as two distinct indicators of MDSS-success in the analysis.

\subsection{Satisfaction}

Table 2 shows that in the multivariate analysis three of the independent variable have a significant effect in the expected direction. Satisfaction with the MDSS is higher as the perceived participation of the users in the development process of the MDSS is higher (HS 8), as the MDSS is more adaptable (HS 10 ), and when the MDSS is used through direct interaction (HS 13). The variable involvement in automation shows an (almost) significant effect in the opposite direction from HS 6: managers with higher levels of involvement with automation tend to be less satisfied with their MDSS instead of more. The explanation for this unexpected result might be that the MDSS of the companies in the study have only a modest level of sophistication (on average, 2.28 on a scale running from 0 to 4 ). Respondents with more computer experience might be disappointed with such (relatively) low-level systems. An outcome supporting the explanation that the current systems are relatively unsophisticated ('too simple') is the (also unexpected) negative relationship between education and satisfaction. Although this effect is not significant, it suggests that managers with more education derive less satisfaction from working with an MDSS.

Of the remaining eight (non-significant) variables, six had signs in the hypothesized direction. The two variables for which this does not apply, age and whether or not the MDSS was purchased as a commercial package, are far from significant.

Two variables: the role of marketing in the purchase/development process and sophistication, which are not significant in the multivariate analysis, show a significant bivariate relationship with satisfaction in the hypothesized direction (i.e., in agreement with HS 7 and HS 11).

\section{What do we learn from this study?}

Measured from the insights that we had before, as formulated in the hypotheses, what do we learn from the results of this empirical study about the factors that determine adoption and success of (marketing) decision support systems?

(i) First of all we can conclude that the factors that determine the adoption of an MDSS are different from the factors that affect the success of an MDSS, once it is implemented. As Tables 1 and 2 show, for adoption the external environment, organizational, and task environment factors are most important, whereas for implementation success, the key variables are user factors and (even more so) implementation factors. Our results suggest that it is not an important limitation if, in studies of DSS success, these 'contextual' variables are left out, as seems to 
be the case quite often (Alavi and Joachimsthaler, 1992). The managerial implication of this finding is that different instruments have to be used if it is desired to stimulate the adoption of an MDSS than if the objective is to implement an MDSS that is as successful as possible. For the first purpose, top management support and communication about MDSS is very important. For implementation success one should pay much attention to factors such as sophistication, adaptability and participation.

(ii) With respect to the factors that affect adoption of an MDSS, support, communication, and knowledge about MDSS are key. Top management support, a favorable attitude towards MDSS in the marketing department (as demonstrated by the support from colleagues), information sources about MDSS, and the awareness of successful applications of MDSS in other companies are the variables most strongly related to adoption and adoption intention. The phenomenon, often reported in the literature, that larger and more sophisticated companies are more likely to have an (M)DSS can largely be explained by the fact that in larger and more sophisticated companies there is more (top-) management support for MDSS, the attitudes in the marketing department towards MDSS are more favorable, and there is more knowledge about MDSS.

(iii) MDSS are not adopted primarily to upgrade (add value to) existing information, as we expected, but for a more mundane purpose, i.e., to obtain information. One of the reasons that companies want MDSS is lack of information about their markets. And companies with an MDSS do report higher levels of market information than companies without an MDSS $(p=0.06)$. So MDSS seem to deliver on this requirement of providing information.

(iv) Although, so far, companies in consumer goods have more often implemented MDSS than companies in the business-to-business sector, in the future this difference is likely to disappear: adoption intention with respect to MDSS among business-tobusiness firms is not lower than among consumer goods companies. A possible explanation is the strong emergence of data-base marketing techniques (and related technology for customer loyalty and relationship marketing) which are especially well-suited to industrial marketing companies. This technology provides these firms with very rich data about their customers and can be used as the basis for building marketing information and decision support systems.

(v) Of the factors that affect implementation success of an MDSS, the implementation factors are more important than the user factors. User factors have been studied extensively in the DSS-literature, typically with a research design of having one particular (M)DSS and a group of different respondents using this MDSS (a typical example is the Zinkhan et al., 1987 study). Since in the present study we have a broad sample of, in principle, 194 different MDSS with different implementation characteristics, we are in a better position to examine the effect of these implementation factors on MDSS-success. Factors such as whether or not the MDSS is used by direct interaction, the sophistication of the MDSS, the adaptability of the MDSS (a very important factor as John Little already suggested in 1970), and the perception of the user that they participated in the development and implementation process of the MDSS turn out to be more important for MDSSsuccess than user factors such as age and involvement in automation (see the beta values in Table 2). This result implies that in future (M)DSS research, more attention is warranted for implementation factors than for user factors. This is in agreement with the statement of Srinivasan and Davis (1987) that in future studies of DSS much attention should be paid to the mechanisms for the facilitation and support of users (implementation factors).

The managerial implication of this finding is that when making plans for the development and installation of an MDSS in a company, one should pay more attention to implementation issues such as the involvement of the user, the sophistication and adaptability of the MDSS, and make sure that every user can directly interact with the system from his or her workplace, than to the selection of users who have the right qualifications to work successfully with an MDSS. This is a fortunate result: one can choose the characteristics of an MDSS and the implementation procedure to a large extent, but the qualifications of the users are mostly given and only variable in the longer run.

(vi) It is not necessarily better for implementation success to develop an MDSS within the company than bringing in a system from outside. Of the MDSS in this study, $31 \%$ were purchased as a 
commercial package from outside, whereas $69 \%$ were developed inside the company. No differences were found between those systems concerning use and satisfaction. This is interesting from a managerial point of view, since purchasing an existing software package usually will be less costly than developing a new one. Also we found that it makes no difference for implementation success whether or not an MDSS is connected to other (information) systems of the company. As mentioned before, the current development is in the direction of company-wide information systems, with modules for various functional areas like marketing, production, and logistics that are connected to each other. It is fortunate to observe that this is at least not a factor that decreases satisfaction with MDSS.

(vii) Involvement with automation does not necessarily increase the satisfaction that one obtains from MDSS. If an MDSS has a low level of sophistication, users with more experience in working with computers and IT may get disappointed. This illustrates the critical role of the sophistication of the MDSS.

(viii) Use of and satisfaction with an MDSS are different quantities with only a limited overlap. Therefore, studies of implementation success of MDSS preferably should include both factors. If there is an effect of one variable on the other, the direction of this effect is not clear. In the present study (looking at the contribution of satisfaction in the multiple regression of use, and vice versa) the effects in both directions are of the same order of magnitude.

(ix) In summary, the practical recommendations that result from our study can be formulated as follows. If the objective is to have an MDSS adopted in a company, top management should actively support such an endeavor, a communication process should be started to inform the people in the marketing department about MDSS and to help develop a positive attitude towards MDSS. Much attention should be paid to the dissemination of knowledge about successful applications of MDSS in other companies. If the objective is to install an MDSS that is as successful as possible, it is important to have the future users play an important role in the implementation process, to make sure that the MDSS has the proper level of sophistication (not too low), and to see that the MDSS can easily be adapted. Also, an MDSS should be designed in such a way that the managers can directly interact with the system from their workplace.

\section{Limitations of this study and items for further research}

\subsection{Possible limitations}

The data for this study were collected in a particular country (The Netherlands) at a particular point in time. There are no reasons why the mechanisms underlying the adoption and use of, and satisfaction with MDSS would be different in The Netherlands from other countries with a similar economy. As we saw in the introduction, the adoption level of MDSS in The Netherlands does not differ much from the adoption level in the US. The data in the data base used in this study were collected in 1990, and it is quite likely that since then the actual level of MDSS adoption has gone up. However, it is our contention that the basic mechanisms behind adoption, use and satisfaction, which is the essential focus of this paper, is relatively stable. This research fits in a long term tradition of adoption/implementation studies of (M)DSS that started more than twenty years ago.

Second, there are the potential limitations of our sample. However, our sample size $(n=525)$ is large, compared to other empirical studies in the DSS and marketing literature (Zmud, 1982; Davis, 1989; Gatignon and Robertson, 1989; Cooper and Zmud, 1990).

Consequently our statistical tests have a considerable power. One should realize, though, that with such a large sample the size of observed effects can be quite modest, even if they are significant.

Third, there are limitations with respect to our measurement procedures. Since there are constraints to the length of a (telephone) interview, we were not able to take multiple measurements for all of our variables. For variables such as satisfaction and use, multiple measurements would have been better. Scales for perceived usefulness and perceived case of use for (M)DSS are now available (Davis, 1989; Adams et al., 1992).

Finally, one should realize that we interviewed 
only one person in a company: the marketing manager. For some questions we might have obtained different answers if we had talked to general managers or information systems people.

In conclusion we feel that the limitations of this study are not prohibitive with respect to the insights that it offers.

\subsection{Further research}

Taking into consideration the outcomes as well as the limitations of this study, the following directions can be suggested for future research on adoption and success of marketing decision support systems.

(i) In this study only one respondent per company was interviewed. It would be interesting to carry out multi-respondent studies, where in a particular company several users of the MDSS, including marketing and/or marketing research people, are interviewed. Since it was found in the present study that in many cases persons outside the marketing domain play an important role in adoption and implementation of the MDSS, especially top management and persons from the IT-department, it would be interesting to include them in the study.

(ii) It was found that implementation factors are very important for the success of MDSS. Therefore a closer look seems to be warranted with respect to the actual procedures companies apply to stimulate the adoption and acceptance process of MDSS. How, for example, does top management support MDSS? Is it with moral support, budgets, hiring people with specific skills, giving rewards? How are employees stimulated to become familiar with MDSS? Are they sent to outside seminars or is an attempt made to find an internal 'MDSS-champion' who preaches 'the gospel'? What is the role of the suppliers of MDSS-technology? Some of these approaches probably are more effective than others. Therefore, it would be worthwhile to study the communication processes with respect to MDSS in companies and try to learn from that what works and what does not work.

(iii) In the present study we have only two variables to measure implementation success, use and satisfaction. In their article "Information Systems Success: the Quest for the Dependent Variable",
Delone and McLean (1992) develop a much more elaborate concept of information success, consisting of a hierarchy of constructs: system quality, information quality, use, user satisfaction, individual impact and organizational impact. In future work on MDSS it would be recommendable to take such a more comprehensive approach, applying several different constructs for information system success and develop multi-item scales for each of these constructs.

(iv) In the current study we have taken a broad approach and included basically all industries. In this way a large amount of variance was introduced with respect to the types of MDSS, organizational factors, task environment factors, user factors, and probably also implementation factors. As a next step, in-depth studies of the adoption and success of MDSS in particular industries might be considered, for example, in fast moving consumer goods, consumer durables, the pharmaceutical industry, high tech industries, and the IT and telecommunication industry. Within the context of a particular industry, the effects of specific variables can be observed much better. Also, we might find that some variables have different effects in different industries.

(v) This study looked at the MDSS of a company at one moment in time. However, MDSS develop over time, both as a result of experience with MDSS in companies and the (fast) development of MDSStechnology (data-base management systems, computer and telecommunication technology, specific software packages, etc). From time to time, companies will have to renew their MDSS. At this moment some companies already have their third 'generation' of MDSS, and this process could be followed and examined over time. Interesting questions are: when does a company decide to renew its MDSS, are the factors leading to renewal the same as the factors that led to the adoption of the MDSS in the first place, and do we see an increase in sophistication of the MDSS of a company over time? To get a picture of these dynamics of MDSS over time, carrying out observations at the same companies at different moments in time, with intervals of three to five years should be considered.

We hope that the results from this study and the research directions outlined above will encourage other researchers to take up work in this area and further extend our insights with respect to the adop- 
tion and success of marketing decision support systems.

\section{Appendix A. Description of the variables and the way they were measured}

\section{A.1. Dependent variables}

Adoption: $1=$ yes; $0=$ no.

Assessment was based on the response to the question: "Does your company have a system that is used or could be used by different persons in the organization that could be considered as a marketing decision support system?' (Before that a relatively broad definition of a marketing decision support system had been given emphasizing that MDSS can exist under many different forms and names.)

Adoption intention (among non-adopters): four point scale: $1=$ absolutely not; $4=$ definitely yes.

Use: Average number of hours per week that the respondent is using the MDSS, directly (i.e. interactively) or indirectly.

Satisfaction with the MDSS: 1 = very unsatisfied; $5=$ very satisfied.

\section{A.2. Independent variables}

When possible, sets of independent variables were grouped into meaningful underlying factors. Judgments on whether or not this is possible were based on the Kaiser-Meyer-Olkin Measure for Sampling Adequay and Cronbach $\alpha$. Alpha values for constructs given in this Appendix are standardized item alphas. In order to obtain factors that explain as much variance of the underlying variables as possible, principal components factor analysis was used. It has been tried to find an acceptable trade-off between the loss of information by grouping variables into factors and the objective to make the results as parsimonious as possible.

\section{External environment factors}

\section{ENVDYN}

Derived from the following variables:

- Product change: degree of change in the products the company is offering: $1=$ (almost) no change; $5=$ very much change.
- Competition change: degree of change in the competitive environment (same scale).

- Customers change: degree of change in the customers of the company (same scale).

$\alpha=0.65^{7}, \mathrm{KMO}^{8}=0.60$.

BBCONSMA = Predominantly business-to-business marketing (1) or consumer marketing (0).

Organizational factors

COMPSIZE

Derived from the variables:

- Annual revenue of the company.

- Number of employees.

$\alpha=0.76, \mathrm{KMO}=0.66$.

CENTRAL: degree of centralization: $1=$ very decentralized; $5=$ very centralized.

TOPMSUPP: degree of support from top management for MDSS: 1 = very little; 5 = very much.

Task environment factors

\section{MARKORG}

Derived from the variables:

- Marketing department: the existence of one or more separate marketing departments (1) or not (0).

- Marketing research department: whether (1) or not $(0)$ the company has a marketing research department (possibly as part of the marketing department).

- Marketing plan: whether (1) or not (0) the company works with an annual marketing plan.

$$
\alpha=0.70, \mathrm{KMO}=0.66 \text {. }
$$

MRESOURC

Derived from the variables:

- Size of the marketing staff.

- Number of supporting employees in the marketing department.

- Hardware in the marketing department: number of PC's, terminals and/or workstations.

- Software: number of specific software packages available for marketing.

$\alpha=0.46, \mathrm{KMO}=0.66$.

INFO

\footnotetext{
${ }^{7}$ Cronbach $\alpha$.

${ }^{8}$ Kaiser-Meyer-Olkin Measure of Sampling Adequacy.
} 
Derived from:

- Information about markets: $1=$ very little; $5=$ very much.

- Information about customers: $1=$ very little; $5=$ very much.

- Information about competition: $1=$ very little; $5=$ very much.

- Information about distribution channels: $1=$ very little; $5=$ very much.

$\alpha=0.48, \mathrm{KMO}=0.59$.

COLLSUPP: degree of support for MDSS from colleagues in the marketing department $(1=$ very little; 5 = very much).

INFOSRCS: number of different information sources about MDSS.

SUCCOTHR: knowledge of successful application(s) of MDSS in other companies $(1=$ yes; $0=$ no).

\section{User factors}

AGE: ages of respondent in years.

EDUC: education level of respondent $(1=$ academic; $0=$ non academic).

EXPER: number of years the respondent has experience in the company.

INVAUT: involvement in automation $(1=$ very low; $5=$ very high).

\section{Implementation factors}

COMMPACK: MDSS purchased as commercially available package (1) or developed in the company (0).

MARKROLE: major role in the purchase/development process of the MDSS by marketing ( $1=$ yes; $0=$ no).

PERCPART: perceived participation of the user in the implementation process of the MDSS.

MDSSCHMP: MDSS champion in the company $(1=$ yes; $0=$ no $)$.

ADAPT: adaptability of the MDSS $(1=$ very rigid; $3=$ very adaptable).

CONNECT: whether (1) or not (0) the MDSS is connected to other systems in the company.

SOPHISIC: the type of questions an MDSS can answer according to the continuum: What, Why, What-if and What-should. The actual level of sophistication is determined by Guttman scaling of the features of MDSS (see Wierenga et al., 1994). The score runs from 0 (low sophistication) to 4 (high sophistication).
INTERACT: whether (1) or not (0) the respondent interacts directly with the system. (Indirect use is obtaining information from the MDSS through an intermediary, e.g. an assistant.)

\section{References}

Adams, D.A., Nelson, R.R., Todd, P.A., 1992. Perceived usefulness: Ease of use, and usage of information technology. A replication. Management Information Systems Quarterly 16, 227-247.

Alavi, M., 1982. An assessment of the concept of decision systems as viewed by senior-level executives. Management Information Systems Quarterly 6, 1-9.

Alavi, M., Joachimsthaler, E.A., 1992. Revisiting DSS implementation: A meta-analysis of the literature and suggestions for researchers. Management Information Systems Quarterly 16.

Barki, H., Huff, S.L., 1990. Implementing decision support systems: Correlates of user satisfaction and system usage. Infor (Canada) 28 (2), 89-101.

Baroudi, J.J., Olson, M.H., Ives, B., 1986. An empirical study of the impact of user involvement on system usage and information satisfaction. Communications of the ACM 29 (3), 232238.

Blattberg, R.C., Glazer, R., Little, J.D.C. (Eds.), 1994. The Marketing Information Revolution. Harvard Business School Press, Boston, MA.

Cooper, R.B., Zmud, R.W., 1990. Information technology implementation research: A technological diffusion approach. Management Science 56, 123-139.

Davis, F.D., 1989. Perceived Usefulness, Perceived Ease of Use and User Acceptance of Information Technology. Management Information Systems Quarterly 13, 319-340.

Delone, W.H., McLean, E.R., 1992. Information systems success: The quest for the dependent variable. Information Systems Research 3 (1), 60-95.

Ewusi-Mensah, K., 1981. The external organizational environment and its impact on management information systems. Accounting, Organizations and Society 6 (4), 301-316.

Gatignon, H., Robertson, T.S., 1989. Technology diffusion: An empirical test of competitive effects. Journal of Marketing 53 (1), 35-49.

Gelderman, M., 1995. Factors Affecting The Success Of Management Support Systems. Unpublished Working Paper, Series Research Memoranda, Free University of Amsterdam, May.

Higby, M.A., Farah, B.N., 1991. The status of marketing information systems, decision support systems and expert systems in the marketing function of U.S. firms. Information and Management 20, 29-35.

Ives, B., Olson, M.H., 1984. User involvement and MIS success: A review of research. Management Science 30 (5), 586-603.

Kennedy, A.M., 1983. The adoption and diffusion of new industrial products: A literature review. European Journal of Marketing 17, 31-88.

King, W.R., Rodriquez, J.I., 1981. Participative design of strategic 
decision support systems: An empirical assessment. Management Science 27, 717-726.

Kwon, T.H., Zmud, R.W., 1987. Unifying the fragmented models of information systems implementation. In: Boland, R.J., Hirschheim, R.A. (Eds.), Critical Issues in Information Systems Research. John Wiley, New York.

Lee, J., Kim, S.H., 1992. The relationship between procedural formalization in MIS development and MIS success: A contingent analysis. Information and Management 22, 89-111.

Lilien, G.L., Kotler, P., Moorthy, K.S., 1992. Marketing Models. New York.

Little, J.D.C., 1970. Models and managers: The concept of a decision calculus. Management Science 16, B466-B485.

Little, J.D.C., 1979. Decision support systems for marketing managers. Journal of Marketing 43, 9-26.

Lucas, H.C., Jr., 1975. Why Information Systems Fail. New York.

Lucas, H.C., Jr, Walton, E.J., Ginzberg, M.J., 1988. Implementing Packaged Software. Management Information Systems Quarterly $12,537-549$.

Mohan, L., Holstein, W.K., 1994. Marketing decision support systems in transition. In: Blattberg, R.C., Glazer, R., Little, J.D.C. (Eds.), The Marketing Information Revolution. Harvard Business School Press, Boston, MA, pp. 230-253.

Montazemi, A.R., 1988. Factors affecting information satisfaction in the context of the small business environment. Management Information Systems Quarterly 12, 239-256.

Moriarty, R.T., Swartz, G.S., 1989. Automation to Boost Sales and Marketing. Harvard Business Review, 100-108.

Sawtooth, 1989. Ci2 System, Version 2. Sawtooth Software, Inc., Ketchum, ID.

Schultz, R.L., Slevin, D.P., 1975. Implementation and organizational validity: An empirical investigation. In: Schultz, R.L., Slevin, D.P. (Eds.), Implementing Operations Research/ Management Science. American Elsevier, New York, pp. 153-181.

Shaw, R., 1994. How To Transform Marketing Through IT. London.

Srinivasan, A., Davis, J.G., 1987. A reassessment of implementation process models. Interfaces $17(3), 64-71$.
Sviokla, J., 1989. Business implications of knowledge-based systems. In: Sprague, R.H., Watson, H.J. (Eds.), Decision Support Systems: Putting Theory into Practice. Prentice Hall, Englewood Cliffs, pp. 125-151.

Swanson, E.B., 1994. Information systems innovation among organizations. Management Science 40, 1069-1091.

Taylor, R.N., 1975. Age and experience as determinants of managerial information processing and decision making performance. Academy of Management Journal 18 (1), 74-81.

Udo, G.J., Davis, J.S., 1992. Factors affecting decision support systems benefits. Information and Management 23, 359-371.

Van Bruggen, G.H., 1993. The Effectiveness Of Marketing Management Support Systems. Eburon Publishers, Delft.

Van Bruggen, G.H., Smidts, A., Wierenga, B., 1996. The impact of the quality of a marketing decision support system: An experimental study. International Journal of Research in Marketing 13 (4), 331-344.

Van Campen, P.A.F.M., Huizingh, K.R.E., Oude Ophuis, P.A.M., Wierenga, B., 1991. Marketing Decision Support Systemen bij Nederlandse Bedrijven. Eburon, Delft.

Vasarhelyi, M.A., 1977. Man-machine planning systems: A cognitive style examination of interactive decision making. Journal of Accounting Research 15 (1), 138-153.

Wierenga, B., Oude Opthuis, P.A.M., Huizingh, K.R.E., Van Campen, P.A.F.M., 1994. Hierarchical scaling of marketing decision support systems. Decision Support Systems 12 (3), 219.

Zaltman, G., Duncan, R., Holbek, J., 1973. Innovations in Organizations. New York.

Zinkhan, G.M., Joachimsthaler, E.A., Kinnear, T.C., 1987. Individual differences and marketing decision support usage and satisfaction. Journal of Marketing Research 24(May), 208-214.

Zmud, R.W., 1979. Individual differences and MIS success: A review of the empirical literature. Management Science 25(10), 966-975.

Zmud, R.W., 1982. Diffusion of modern software practices: Influence of centralization and formalization. Management Science 28 (12), 1421-1431. 